Fanum

Sociológico

\section{Forum Sociológico}

Série II

$25 \mid 2014$

Número 25

\title{
Animação Sociocultural: imprecisões, ambiguidades, incertezas e controvérsias de uma ocupação profissional
}

António Manuel Rodrigues Ricardo Batista

\section{OpenEdition}

Journals

Edição electrónica

URL: https://journals.openedition.org/sociologico/898

DOI: $10.4000 /$ sociologico.898

ISSN: 2182-7427

Editora

CICS.NOVA - Centro Interdisciplinar de Ciências Sociais da Universidade Nova de Lisboa

Edição impressa

Paginação: 23-31

ISSN: 0872-8380

Refêrencia eletrónica

António Manuel Rodrigues Ricardo Batista, «Animação Sociocultural: imprecisões, ambiguidades, incertezas e controvérsias de uma ocupação profissional», Forum Sociológico [Online], 25 | 2014, posto online no dia 10 novembro 2014, consultado o 29 março 2022. URL: http://journals.openedition.org/ sociologico/898; DOI: https://doi.org/10.4000/sociologico.898

Este documento foi criado de forma automática no dia 29 março 2022.

(C) CICS.NOVA 


\title{
Animação Sociocultural: imprecisões, ambiguidades, incertezas e controvérsias de uma ocupação profissional
}

\author{
António Manuel Rodrigues Ricardo Batista
}

\section{Animação Sociocultural: imprecisões, ambiguidades e incertezas}

1 A Animação Sociocultural constitui uma atividade imprecisa, ambígua e incerta. Imprecisa, por ser difícil delimitar os seus contornos. Ambígua, pelos múltiplos sentidos atribuídos ao conceito e que resultam, por um lado, de posicionamentos ideológicos diferentes e, por outro lado, da grande diversidade de âmbitos, de contextos e de públicos a quem a atividade se dirige, bem como da grande variedade de instrumentos que utiliza e de atividades que desenvolve. Incerta, pelo caráter transitório de muitos dos seus trabalhos.

2 Na verdade, "não há um autor que se tenha preocupado com o conceito de animação sociocultural que, em seguida, não tenha reconhecido a polissemia, a ambiguidade, a imprecisão, o caráter vago... no uso da expressão" (Trilla, 2004: 25). o mesmo é reconhecido por Quintas e Castaño (1998: 17) quando afirmam que "o conceito de animação é bastante impreciso. Não existe unanimidade entre os autores”. Há, com efeito, segundo Lopes (1993: 79), uma “conflitualidade teórica à volta do conceito", conferindo aos autores perspetivas de abordagem diferentes.

3 Num artigo intitulado "Sobre a Definição de Animação Sociocultural”, Azevedo (2008), após colocar várias interrogações - "A animação sociocultural poderá ser uma ciência? Poderá ser um ramo das ciências sociais? O que é a animação sociocultural? Será uma técnica, um método ou uma ciência?" -, reconhece "que a mesma é um diamante em bruto que carece de ser lapidado de forma a otimizar a sua apresentação e aplicação 
social". Por seu lado, Ander-Egg define-a como "um conjunto de técnicas sociais que, baseadas numa pedagogia participativa, tem como finalidade promover práticas e atividades voluntárias" (1986: 125), apresentando-a "como uma criação frente às atonias do corpo social" (1999: 69-77). Adianta, ao mesmo tempo, trinta e duas definições de vários autores, referindo que a maior parte delas "expressam um projeto pedagógico de consciencialização, de participação e de criatividade social" e "cada um, conforme as suas próprias perspetivas ideológicas/políticas/científicas e a sua própria prática, poderá escolher ou rejeitar" (1999: 69-77). Maria de Lourdes Lima dos Santos (1998: 249), sintetizando a actividade, refere o seguinte:

“(...) torna-se difícil precisar os seus limites e delimitar os seus contornos. Na maior parte dos casos, procede-se de uma das três formas: por exemplificação/ inventariação, definindo o conceito pelas atividades que engloba; pela negativa, eliminando as atividades que não se enquadram no seu âmbito; ou, ainda, pelo considerar do seu caráter residual: na Animação cabe, então, um imenso «território - resto» de práticas de difícil classificação."

\section{Animação Sociocultural e transformações sociais}

\section{Origem da animação enquanto intervenção social, educativa e cultural}

4 A animação, enquanto "processo de dar vida, de infundir alma a alguém ou alguma coisa; ato ou efeito de animar ou de se animar"' entanto, a origem do conceito de animação, enquanto prática ligada à intervenção social, educativa e cultural, surge somente a partir de meados do século XX, mercê da recomposição do tecido social provocada pelo nascimento das sociedades industriais $\mathrm{e}$ da desintegração das chamadas sociedades tradicionais, com todos os problemas que uma alteração dessa natureza acarretou em termos de integração social, de participação comunitária, de comunicação interpessoal e de identidade cultural, indicação que é partilhada pelos vários autores (Ander-Egg, 1999, 2008; Lopes, 2006; Thery, 1970; Tracana, 2006; Ventosa, 2007). Problemas que ganharam expressão à medida a que se ia assistindo à passagem de uma sociedade localizada (em que as identidades se confinavam, basicamente, ao território e à língua) para uma sociedade globalizada (em que as identidades passaram a apresentar um caráter transterritorial, multilinguístico e multimédia), assente em redes de comunicação virtuais (Gonzalez, 2008: 6).

\section{Animação Sociocultural em Portugal}

No caso português, a Animação Sociocultural tem-se traduzido em diferentes formas de intervenção, formas essas que expressam as várias conceções da atividade (Lopes, 2006: 156, 2008a: 457-485 e 2008b: 147-158). Ela começa a ganhar alguma consistência a partir dos anos 60, mercê das novas dinâmicas sociais e económicas que o país começara a conhecer. No entanto, em resultado dos condicionamentos em matéria de direitos, liberdades e garantias dos cidadãos, "a única "animação» permitida era preconizada pela Fundação Nacional para a Alegria no Trabalho (FNAT)” (Ventosa, 2006), cujo propósito era propagandear os ideais do regime político - expressos na tríade "Deus, 
Pátria e Família" - através da organização de colónias de férias, de excursões, de demonstrações desportivas, de conferências, entre outras atividades.

Tendo como pano de fundo uma perspetiva de cultura nacional assente numa conceção nacionalista de Portugal, a criação da FNAT, inspirada no Movimento Internacional Alegria e Trabalho, ao promover "o aproveitamento do tempo livre dos trabalhadores portugueses por forma a assegurar-lhes o maior desenvolvimento físico e a elevação do seu nível intelectual e moral" ${ }^{4}$, tem em vista, como refere Daniel de Melo (2001: 62), a "integração do mundo laboral na orgânica corporativa do Estado Novo", baseada numa perspetiva de conciliação entre o trabalho e o capital e de recusa dos antagonismos sociais e do conflito social, e cujas ações eram preparadas com referência a uma matriz ruralista que se insere num programa político de cultura "espiritual" dos portugueses (Melo, 2001; Ramos do Ó, 1993, 1999; Rosas, 1994; Valente, 1999).

7 O papel da FNAT - convergindo com a ação do Secretariado de Propaganda Nacional/ Secretariado Nacional de Informação e das Casas do Povo/Junta Central das Casas do Povo - inscreve-se num trabalho de imposição autoritária de um projeto doutrinário totalizante para a sociedade portuguesa, consubstanciado através de medidas institucionais consagradoras de uma pretendida unicidade político-ideológica. Através desse projeto, o Estado Novo procura, de acordo com Rosas (1994: 281), "moldar todos os níveis da sociedade civil de acordo com os «novos valores», isto é, tentará educá-la e formá-la imperativamente na moral nacionalista, corporativa e cristã, que haveria de presidir à política, às relações de trabalho, aos lazeres, à vida em família, à educação dos jovens ou à cultura em geral."

8 As mudanças que se vão sucedendo na sociedade portuguesa do pós-guerra (Rosas, 1994: 419-501) - resultantes de um processo de industrialização, urbanização e terciarização que vai ganhando forma - transportam consigo novas questões sociais que, ao longo da década de 50, provocariam um reajustamento na linha de orientação do corporativismo, perdendo importância a perspetiva ruralista e ganhando uma crescente expressão a linha industrialista, através dos Planos de Fomento e consubstanciada no Plano de Formação Social e Organização Corporativa.

9 Não obstante a abertura que se fez sentir na "Primavera Marcelista", a ideia nacionalista da cultura nacional não foi colocada de parte. Ela perdurou até ao 25 de Abril de 1974. Portugal mantinha-se, no dizer de Barreto, “(...) muito mais do que qualquer país, (...) numa espécie de atabafante unidade: um povo com uma só etnia, uma só religião, uma só fronteira, uma só língua, uma só cultura, uma só raça - se assim me posso exprimir -, um só Estado." ${ }^{5}$

10 No período de 1974 a 1980 assiste-se à institucionalização da Animação Sociocultural. Esta é centralizada em instituições criadas expressamente para o efeito, assumindo o Estado a gestão e o controlo das atividades e a formação dos animadores. Dentro deste período, Lopes (2006: 157-239) distingue duas fases na Animação Sociocultural: a "fase revolucionária", que decorre entre 1974 e 1976, e a "fase constitucionalista", entre 1977 e 1980. Na primeira fase, assiste-se a uma intensa atividade de animação, coordenada pela Comissão Interministerial para a Animação Sociocultural (CIASC). Na segunda fase, a ação da Animação Sociocultural é determinada por instituições que assumiram a centralidade da mesma, constituindo o Fundo de Apoio aos Organismos Juvenis (FAOJ) e o Instituto Nacional para o Aproveitamento dos Tempos Livres dos Trabalhadores (INATEL) ${ }^{6}$ exemplos dessa centralidade. 
11 Entre 1981 e 1990, a conceção de Animação, que anteriormente passava por dar expressão a uma ideia de cultura una e homogénea, evoluiu para o reconhecimento de uma cultura com dimensão plural e diversificada, pois

“(...) com a emigração, o turismo, o regresso dos retornados, a abertura democrática, a diversidade de investimentos, a criação de grupos e empresas privadas, os partidos políticos e as associações, a televisão, a integração europeia... com tudo isto, de repente há mesquitas, as sinagogas têm nova vida, nascem seitas, surgem novos cultos, aparecem igrejas protestantes; há sindicatos diversificados e plurais, opiniões diferentes, novos credos e crenças... Isto é, está em construção uma sociedade finalmente plural..."7

12 Neste período, a Animação passa gradualmente da esfera do poder central para a esfera do poder local. Também nesta década Lopes (2006: 240-276) identifica duas fases da Animação Sociocultural: a "fase patrimonialista", que decorre entre 1981 e 1985, em que o Estado se mantém ainda como o grande impulsionador da atividade, através da Secretaria de Estado da Cultura, do FAOJ e da Junta Central das Casas do Povo, caracterizando-se esta fase por uma intervenção centrada na preservação e recuperação do património cultural; a "fase da deslocação da Animação Sociocultural do poder central para o poder local", que decorre entre 1986 e 1990, em que o poder local passa a assumir um crescente interesse e um papel relevante na Animação Sociocultural, encarando-a como uma maneira de mobilizar vontades e recursos.

De 1991 a 1995, assiste-se ao crescimento do fenómeno da imigração, não só dos países africanos de língua oficial portuguesa, mas também do Brasil, dos países da Europa do Leste, da China e da Índia. Nestas circunstâncias, a intervenção da Animação Sociocultural passa a dar expressão à dimensão multicultural (Lopes, 2006: 277-287).

14 A partir de meados dos anos 90, em resultado das transformações ocorridas num mundo cada vez mais globalizado, é posta à prova a capacidade da Animação Sociocultural para enfrentar os novos e complexos desafios. E pese embora, no dizer de Ander-Egg (2008: 20-21), a insuficiente valorização atribuída à Animação Sociocultural em termos de políticas públicas, não deixou de se alargar a intervenção dos Animadores Socioculturais nem os seus perfis profissionais de se ampliarem (Ferreira, 2008: 200).

15 A este respeito, Dinis (2007) situa a Animação Sociocultural num terreno "flexível" e por natureza "criativo". Por sua vez, Azevedo (2009), sublinhando a flexibilidade apontada por Dinis, acrescenta o perfil do "animador empreendedor", como sendo aquele que "desenvolve a actividade em diferentes cenários e posições organizacionais". Já Correia (2008), ao traçar o “perfil do Animador Investigador”, realça um conjunto de requisitos pessoais e profissionais que remetem, nomeadamente, para o "mundo cívico", o "mundo inspirado" e o "mundo de projetos" (Boltanski \& Thévenot, 1991; Boltanski \& Chiapello, 1999; Boltanski, 2001).

16 A atuação em novos campos de intervenção parece traduzir, pois, a capacidade de adaptação e flexibilidade dos Animadores Socioculturais perante experiências de trabalho que apresentam - muitas delas - um caráter transitório e uma grande diversidade em termos das competências exigidas. O que parece corresponder à indicação dada por Lopes (2008a) quando, em matéria de empregabilidade, escreve que

"entre os anos 60 e 90 existiu emprego em Animação. No século XXI vai existir muito trabalho em Animação, mas não o modelo de emprego do século XX, isto requer preparar os Animadores para um novo conceito de empregabilidade assente no trabalho em rede e não no trabalho por conta de outrem, na criação de empresas que respondam ao pulsar do novo tempo e que os contratos programa com lares, 
hospitais, jardins de infância, autarquias, organizações governamentais, deem respostas aos diferentes âmbitos de Animação existentes e ainda os que hão de vir, porque o movimento da vida vai sempre gerar novas necessidades e consequentemente novos âmbitos."

17 Ao traduzir uma mudança de paradigma em matéria de trabalho, a indicação dada ajusta-se, assim, a um mundo em que o futuro se encontra completamente em aberto. Por um lado, a lógica do "trabalho em rede" tende a difundir-se cada vez mais, parecendo constituir-se como o centro do sistema. Por outro lado, o fosso que separa a decisão do conhecimento parece acentuar-se, ou seja, um mundo que impõe a cada "um de nós o fardo de ter de tomar decisões cruciais que podem afetar a nossa sobrevivência sem qualquer base de conhecimento adequado" e, por vezes, "sem ter consciência das suas consequências" (Žižek, 2007: 450-451). Em muitos casos, a incerteza que caracteriza o mundo moderno de hoje torna difícil prever os resultados das decisões que os indivíduos possam tomar (sejam pessoais, sejam profissionais), requerendo a aquisição de novas capacidades que os tornem adaptáveis e flexíveis. É isto, aliás, que ressalta da análise dos discursos proferidos em Animação Sociocultural: a importância que a lógica de projeto (Boltanski e Chiapello, 1999; Boltanski, 2001) parece estar a ganhar em matéria de emprego. E, a ser assim, a empregabilidade dos Animadores passará a estar condicionada pela capacidade de estes se movimentarem na "rede", ou seja, a prova da sua grandeza passará a ser dada pela sua capacidade de adaptação e flexibilidade perante experiências de trabalho que tendem a apresentar um caráter transitório e uma grande diversidade em termos das competências exigidas.

Esta tendência, fazendo-se sentir nos vários setores de intervenção da Animação Sociocultural, assume grande expressão no setor cultural, conforme realça Gomes (2010: 118). Refere este autor que o aumento das oportunidades de trabalho neste setor vem sendo associado a uma maior flexibilidade e precariedade dos vínculos e prestações de trabalho, assim como à emergência ou consolidação de novas funções e modos de organização do trabalho marcados pela polivalência e cumulatividade. Aliás, os dados do Observatório das Actividades Culturais indicam que a crescente difusão das formas flexíveis de trabalho, registada ao longo dos anos 80 e 90, se articula de um modo muito estreito com o aumento da oferta cultural e, nessa medida, com o acréscimo de emprego e de oportunidades de trabalho para os diversos profissionais relacionados com o setor, contando-se entre estes os Animadores Socioculturais a trabalharem em contextos culturais diversos, nomeadamente em departamentos de ação cultural de Câmaras Municipais e Juntas de Freguesia. Este aumento da oferta cultural, nomeadamente ao nível das programações das autarquias locais, implica, frequentemente, o estabelecimento de parcerias com associações, fundações e outras entidades, com recurso a formas de trabalho flexíveis, na modalidade de projeto e baseadas em práticas de outsourcing (Gomes \& Martinho, 2009: 151-159; Martinho, 2010: 243-247).

19 O que se regista no setor cultural em geral e na Animação Sociocultural em particular, nas várias vertentes da sua intervenção, inscreve-se num plano mais alargado de uma forte mudança no mundo do trabalho. Mudança que assenta, no caso português, numa crescente representação das formas instáveis de empregar: contratação a prazo/termo, recibos verdes, trabalho temporário, trabalho clandestino, entre outras. Esta mudança começa a desenhar-se a partir da segunda metade dos anos 70 - com a publicação da legislação que regulamenta a contratação a prazo - e ao longo dos anos 80, intensificando-se a partir de meados dos anos 90 . 
O trabalho, enquanto mecanismo de inserção e de integração social e de reconhecimento, garantindo níveis básicos de proteção social, parece, pois, estar sujeito a um processo de fragilização. 0 modelo que tem vindo a ganhar força assenta, em larga medida, no crescimento acentuado das formas de trabalho intermitentes e, não raras vezes, socialmente pouco protegidas. No caso português, a contratação a termo, o trabalho temporário (Pereira, 1988) e a falsa prestação de serviços são exemplos ilustrativos de uma regra e já não de uma exceção na prática contratual.

21 Ao contrário do que sucedia há umas décadas, o mundo do trabalho caracteriza-se presentemente por ser pouco linear (Pais: 2005). Especialmente nas gerações mais jovens, os percursos profissionais são "marcados pela instabilidade e pelo risco" (Guerreiro \& Abrantes, 2004: 28). E muito embora pareça ser crescente a impotência das comunidades locais em atenuar esse risco (Hespanha et al., 2002: 29), importa perceber a maneira como os indivíduos orientam e ajustam a sua ação, ou seja, que tomadas de posição vão assumindo em face das situações concretas de trabalho com que se vão deparando. E são precisamente essas tomadas de posição que os Animadores Socioculturais vão assumindo sobre o caráter justo ou injusto das situações em que se encontram (Boltanski \& Thévenot, 1991: 87), bem como as gramáticas em que as mesmas assentam, que se procurarão aclarar nas várias etapas da investigação em curso.

\section{Animação Sociocultural e controvérsias no espaço público}

22 A informação recolhida até ao momento presente - através de documentos ${ }^{8} \mathrm{e}$ através de entrevistas ${ }^{9}$ - revela, por um lado, uma assinalável diferença entre aquilo que os Animadores Socioculturais gostariam que fosse a Animação e aquilo com que estes na realidade se deparam nos vários contextos de trabalho. Diferença que se faz notar em relação às "licenças" e ao "mandato" (Hughes, 1993; Strauss, 1992), ao "poder profissional" (Freidson, 1986 e 1994), à "jurisdição profissional" (Abbott, 1988) e ao "estatuto profissional", constituindo, por isso, problemáticas que geram tensões e controvérsias entre os profissionais. Por outro lado, a informação recolhida pôs em evidência a diversidade de posições que os atores da Animação Sociocultural assumem face às problemáticas enunciadas, bem como a diversidade de meios utilizados para a sua expressão pública (jornais, revistas, fóruns de discussão, blogs, congressos, encontros, entre outros).

Desta maneira, à luz da perspetiva da Sociologia Pragmática, perspetiva que considera a ação como o produto de um encontro entre as situações/contextos/acontecimentos e as formas como os atores nelas se envolvem em determinados regimes, os Animadores orientam publicamente a sua ação realçando as questões da justiça e do bem comum. $\mathrm{Na}$ verdade, os dados reunidos indicam um efetivo envolvimento destes profissionais em controvérsias em torno de situações problemáticas de justiça e, por via da sua expressão pública, deixam perceber os dispositivos que servem de base às justificações da sua ação e/ou à produção de juízos críticos sobre a ação dos outros. Dispositivos esses que resultam de "diferentes mundos" (cités) justificativos (Boltanski \& Thévenot, 1991; Boltanski \& Chiapello, 1999; Boltanski, 2001), especialmente do mundo cívico, em que o bem coletivo, a promoção da participação na vida da cidade e a igualdade constituem as formas de expressão privilegiadas, dando disso conta os próprios títulos 
de um conjunto de artigos incluídos em várias publicações da Animação Sociocultural. Porém, não deixam de resultar também do mundo industrial, em que são destacados os atributos profissionais da Animação Sociocultural e a sua eficácia, do mundo inspirado, em que a criatividade/inovação, a autenticidade e o espírito artístico são capacidades enaltecidas, e ainda do mundo assente numa lógica de projetos, em que a adaptação e a flexibilidade são atributos indicados como indispensáveis.

Assim, no que respeita às "licenças", a controvérsia gira em torno da sua real importância em termos de exercício da Animação Sociocultural. Não assegurando o controlo no acesso ao exercício da atividade, as licenças não protegem a autoridade e prestígio dos profissionais. Com efeito, nas várias manifestações públicas sobre esta matéria, os Animadores Socioculturais deixam claro um sentimento de injustiça resultante da preferência que é dada aos Animadores com formação secundária em muitos contextos de trabalho em detrimento dos Animadores com formação superior.

Este sentimento de injustiça prende-se, ao mesmo tempo, com a diferença de tratamento entre os licenciados em Animação e outros licenciados no que se refere à remuneração. A explicação para esta diferença de tratamento radica, segundo um participante no ANIMUSFÓRUM de 20 de setembro de 2008, na existência de formações em Animação Sociocultural ao nível secundário, pois “(...) enquanto existirem cursos profissionais na área (...) existe um saco e «colocam-nos» todos lá dentro (...) Se as entidades (...) puderem colocar um Animador do Curso Técnico (é o que fazem porque sai muito mais barato) colocam".

Por sua vez, a "multiplicação desenfreada dos cursos de Animação ao nível do ensino superior, ensino profissional e/ou secundário e outras formações paralelas e a inexistência de um fio condutor entre formações constituem fatores desvalorizadores dos diplomas" (ANIMUSFÓRUM, 20 de setembro de 2008). A grande diversidade de âmbitos, de contextos e de públicos a quem a atividade se dirige e, ao mesmo tempo, a grande variedade de formações e a inexistência de um fio condutor entre elas, leva a que Santos Costa (2010: 14), questionando o perfil ocupacional, o modelo de formação e a definição diferencial da Animação Sociocultural, coloque as seguintes interrogações:

“A Animação Sociocultural é uma profissão específica ou um modelo de intervenção que possa ser utilizado noutras profissões? (...) A Animação Sociocultural deve ter uma formação específica, de animadores, com caráter finalista ou uma formação para a animação, com caráter transversal e incluída em diversos estudos? (...) O que é verdadeiramente específico da Animação Sociocultural? o que faz realmente diferente a Animação Sociocultural em relação a outros modelos de formação?"

Também Bento (2007), sobre a questão de saber que Animadores devem ser formados, se interroga: "Será que o animador cultural para desenvolver a sua atividade profissional deverá ter uma formação académica? Os animadores deverão ter uma formação polivalente ou especializada?". E, logo a seguir, refere que “(...) devem existir, do nosso ponto de vista, animadores culturais sem grau académico. Ao mesmo tempo também pensamos que devem existir animadores culturais com formação académica".

Por seu turno, a reduzida visibilidade dos projetos de Animação Sociocultural parece constituir, no dizer de uma Animadora Sociocultural a trabalhar num Centro de Dia e Centro de Convívio para Idosos de uma Instituição Particular de Solidariedade Social, um fator condicionador do valor atribuído aos diplomas (Entrevista 1 - julho de 2010): “(...) há uma série de projetos de intervenção comunitária, mas eles não têm visibilidade, porque depois ficam neles próprios. (...) dar visibilidade a trabalhos 
comunitários e ao sentido comunitário... talvez... pudesse ser a chave para um maior valor do diploma (...)".

Relativamente ao "mandato", sendo pouco claro, compromete a autonomia e a autoridade profissionais, tornando ambíguo o espaço institucional de atuação dos Animadores Socioculturais. Esta ambiguidade parece estar relacionada, de acordo com as conclusões do debate sobre o Estatuto dos Animadores Socioculturais, promovido pela Associação Regional dos Animadores Socioculturais de Tondela a 9 de março de 2010, "com as especializações existentes no ensino superior", pois estas tornam "mais complicado gerir os conteúdos funcionais do Animador, assim como os seus direitos e deveres". E tal como é referido num documento intitulado "Lexis e Praxis" - produzido pela Escola Superior de Educação de Santarém sobre a orientação estratégica para a reformulação do curso de licenciatura em Animação Cultural e Educação Comunitária -, a carência de saberes científicos na formação dos Animadores constitui uma explicação para a ambiguidade que se faz notar no seu dia a dia profissional: "Animadores são detentores de Processos mas carecem geralmente de formação conteúdal (saberes numa dada área científica...), (...) não se pode ser só detentor de saberes processuais (saber como se deve agir) sem se saber bem sobre o que (conteúdo) se age, ou viceversa."

Em relação ao "poder profissional", sendo frágil, traduz-se numa ausência de controlo sobre a relação com os clientes, a organização do trabalho, o mercado e o conhecimento e, desta maneira, incapacita os profissionais em ditar o conteúdo, os termos e as condições do seu trabalho. Este poder, no dizer de uma professora de um curso de licenciatura em Animação Sociocultural, “(...) tem que ser conquistado pelos Animadores, com certeza, e por eles próprios, enquanto grupo socioprofissional" (Entrevista 6 - julho de 2010). A mesma opinião é partilhada por um dirigente associativo (APDASC - Associação para o Desenvolvimento da Animação Sociocultural, núcleo da região de Lisboa e Vale do Tejo - Entrevista 7 - julho de 2010) ao afirmar que “(...) o Animador tem sobretudo de conquistar o espaço, o espaço não lhe é cedido em função da formação que apresenta, ao contrário do que sucede, normalmente, com o Assistente Social, em que o espaço lhe é cedido em função do curso em que está formado (...)".

31 Em matéria de "jurisdição profissional", sendo vulnerável, explica a intromissão de outros profissionais nas atividades de Animação Sociocultural. Efetivamente, “(...) debaixo da designação Animação temos situações muito diversas, algumas até híbridas" (professora de um curso de licenciatura em Animação Sociocultural - Entrevista 6 julho de 2010).

32 Sobre o "estatuto profissional", percebe-se que a necessidade de existir um estatuto para o reconhecimento da atividade de Animação Sociocultural suscita controvérsia. Por um lado, há a expectativa de que o estatuto possa regular a atividade de Animação Sociocultural e, dessa maneira, constituir um fator disciplinador do mercado, indicando e impondo os requisitos necessários para o seu exercício. Por outro lado, há o receio de que o estatuto possa limitar a atividade de Animação Sociocultural e, desse modo, constituir um fator de exclusão.

Para os defensores do estatuto enquanto regulador da atividade, a sua criação constitui uma medida essencial para

"disciplinar o exercício da profissão do Animador, distinguindo os direitos e deveres do profissional (...)”, uma vez que “(...) terá que ser aprovado por uma 
Associação de Direito Público, representativa dos profissionais do setor, que mais tarde se poderá/deverá transformar em Sindicato ou até mesmo em Ordem Profissional" (conclusões do debate sobre o Estatuto dos Animadores Socioculturais, promovido pela Associação Regional dos Animadores Socioculturais de Tondela em março de 2010).

Associação essa que chamará a si, no dizer dos defensores do estatuto, a prerrogativa de "certificar o perfil e as competências dos profissionais de animação sociocultural", garantindo assim a sua qualidade técnica e pedagógica. Dentro desta linha reguladora, o estatuto terá de conter um corpo normativo que permita "disciplinar as relações que os animadores socioculturais estabelecem entre si, reciprocamente, ou com a comunidade" e, ao mesmo tempo, sancionar os que não cumpram os princípios deontológicos estabelecidos.

Os que receiam que o estatuto constitua um fator de exclusão, referem que “(...) é preciso ter cuidado, o estatuto tanto poderá limitar a atividade, afastando dela pessoas que há muitos anos fazem Animação, pese embora não tenham formação formal (...) (Dirigente da APDASC - Associação para o Desenvolvimento da Animação Sociocultural, núcleo da região de Lisboa e Vale do Tejo - Entrevista 7 - julho de 2010).

Mais contundente é a posição de Esaú Dinis (2010: 179-193) no que diz respeito ao estatuto:

"recuso a criação de dispositivos jurídicos que assegurem um tratamento específico para a Animação Sociocultural e seus profissionais (...) Longe de preconizar códigos deontológicos e estatutos corporativos de reduzida eficácia e natural opacidade, apostaria, antes, que fossem exploradas modalidades de transparência, como o contrato de animação, ou contrato de projeto, em que os dados ficam definidos e se previnem operações de desvio, de ocultação ou manipulativas, sejam na linha do domesticar, sejam no intuito de rutura ou «revolução», seja na contumácia de prolongar rotinas contra a corrente (...)".

\section{Nota final}

Não obstante a Animação Sociocultural acompanhar as grandes transformações sociais ocorridas a partir de meados do século XX, não deixa de ser assinalável a diferença entre aquilo que os Animadores Socioculturais gostariam que fosse a Animação e aquilo com que se deparam nos vários contextos de trabalho: imprecisão, ambiguidade $\mathrm{e}$ incerteza. Essa diferença gera tensões que se traduzem em controvérsias públicas em torno de situações problemáticas de justiça. Desde logo, em torno da (in)definição do próprio conceito de Animação e, articuladamente, em torno das "licenças", do "mandato", do "poder profissional", da "jurisdição profissional" e do "estatuto profissional". Os argumentos que suportam as diversas justificações e/ou os juízos críticos que os Animadores Socioculturais vão produzindo em relação às problemáticas que afetam a atividade assentam sobretudo em dispositivos de ordem cívica. Mas também em dispositivos relacionados com os atributos profissionais e a sua eficácia, com a criatividade/inovação, a autenticidade e o espírito artístico e com a flexibilidade e a capacidade de adaptação a um mundo em que o futuro é uma incógnita. 


\section{BIBLIOGRAFIA}

ABBOTT, A. (1988), The System of Professions - An Essay on the Division of Expert Labor, Chicago e Londres, The University of Chicago Press.

ANDER-EGG, E. (1986), Metodologia y Practica de la Animacion Sociocultural, Buenos Aires, Humanitas.

ANDER-EGG, E. (1999), O Léxico do Animador, Amarante, ANASC - Associação Nacional dos Animadores Socioculturais.

ANDER-EGG, E. (2008), “A Animação Sociocultural e as Perspetivas para o Século XXI” in J. D. L. Pereira et al., A Animação Sociocultural e os Desafios do Século XXI, Chaves, Intervenção - Associação para a Promoção e Divulgação Cultural, pp. 19-32.

ARENDT, H. ([1948] 2006), As Origens do Totalitarismo, Lisboa, Publicações D. Quixote.

AZEVEDO, C. A. S. (2008), "Sobre a Definição de Animação Sociocultural”, in Práticas de Animação, APDASC - Associação para o Desenvolvimento da Animação Sociocultural, Ano 2, n.. 1, outubro de 2008 (http:revistapraticasdeanimacao.google pages.com).

AZEVEDO, C. A. S. (2009), “O Animador Empreendedor”, in Práticas de Animação, APDASC Associação para o Desenvolvimento da Animação Sociocultural, Ano 3, n.o 2, outubro de 2009 (http:revistapraticasdeanimacao.google pages.com).

BAUMAN, Z. ([2005] 2006), Confiança e Medo na Cidade, Lisboa, Relógio D’Água Editores.

BENTO, A. (2007), “Afinal que Animadores devemos formar?”, in Revista Práticas de Animação, ano 1, n. 0 , outubro de 2007.

BOLTANSKI, L. e L. Thévenot (1991), De la Justification : les économies de la grandeur, Paris, Gallimard.

BOLTANSKI, L. e È. Chiapello (1999), Le Nouvel Esprit du Capitalisme, Paris, Gallimard.

BOLTANSKI, L. (2001), “A Moral da Rede? Críticas e Justificações nas Recentes Evoluções do Capitalismo", Fórum Sociológico n.․5/6 (nova série), pp. 13-35.

CORREIA, P. S. (2008), “O Perfil do Animador/Investigador”, in Práticas de Animação, APDASC Associação para o Desenvolvimento da Animação Sociocultural, Ano 2, n.ำ 1, outubro de 2008 (http:revistapraticasdeanimacao.google pages.com).

COSTA, C. Santos (coord.) (2010), Animação Sociocultural - Profissão e Profissionalização dos Animadores, Oliveira de Azeméis, Livpsic.

DINIS, E. (2007), “Animação, Animadores e Metáforas”, in A. N Peres e M. S. C. Lopes, Animação Sociocultural - Novos Desafios, Associação Portuguesa de Animação e Pedagogia (APAP), pp. 47-61.

DINIS, E. (2010), "Princípios Éticos e Deontológicos da Animação Sociocultural e dos Animadores Algumas Pistas", in C. Santos Costa (coord.), Animação Sociocultural - Profissão e Profissionalização dos Animadores, Oliveira de Azeméis, Livpsic, pp. 179-193.

FERREIRA, F. I. (2008), “A Animação Sociocultural e as Transformações no Mundo do Trabalho”, in J. D. L. Pereira et al. (coords.), A Animação Sociocultural e os Desafios do Século XXI, Chaves, Intervenção - Associação para a Promoção e Divulgação Cultural, pp. 192-206. 
FREIDSON, E. (1986), Professional Powers - A Study of Institutionalization of Formal Knowledge, Chicago e Londres, The University of Chicago Press.

FREIDSON, E. (1994), Professionalism Reborn - Theory, Prophecy and Policy, Cambridge, Polity Press.

FREIDSON, E. ([1994] 1998), Renascimento do Profissionalismo: Teoria, Profecia e Política, São Paulo, Editora da Universidade de São Paulo.

GILLET, J.-C. (1995), Animation et Animateurs. Le sens de l'action, Paris, L'Harmattan.

GOMES, T. R. (2010), “Emprego, Democratização Cultural e Formação de Públicos”, in M.a de L. L. Santos e J. M. Pais (orgs.), Novos Trilhos Culturais: Práticas e Políticas, Lisboa, ICS - Imprensa de Ciências Sociais, pp. 115-120.

GOMES, T. R. e T. D. Martinho (2009), Trabalho e Qualificação nas Actividades Culturais. Um Panorama em Vários Domínios, OAC - Observatório das Actividades Culturais (www.oac.pt).

GONZALEZ, M. V. (2008), “La Animación Ante los Retos de la Sobremodernidade”, in Práticas de Animação, APDASC - Associação para o Desenvolvimento da Animação Sociocultural, Ano 2, n.․ 1, outubro de 2008 (http:revistapraticasdeanimacao.google pages.com).

GUERREIRO, M. a D. e P. Abrantes (2004), Transições Incertas: os Jovens perante o Trabalho e a Família, Lisboa, DGEEP - Direção-Geral Estudos, Estatística e Planeamento do Ministério das Atividades Económicas e do Trabalho.

HESPANHA, P. et al. (2002), “Globalização Insidiosa e Excludente. Da Incapacidade de Organizar Respostas à Escala Local”, in P. Hespanha e G. Carapinheiro (orgs.) Risco Social e Incerteza: Pode o Estado Social Recuar mais?, Porto, Edições Afrontamento, pp. 25-54.

HUGHES, E. C. (1993), The Sociological Eye, USA, Transaction Publishers.

LOPES, J. T. (1993), Animação no Espaço Escolar Urbano - um estudo sobre políticas autárquicas de Animação Sociocultural (http://ler.letras.up.pt./ uploads/ficheiro/1310.pdf).

LOPES, M. de S. (2006), Animação Sociocultural em Portugal, Chaves, Intervenção - Associação para a Promoção e Divulgação Cultural.

LOPES, M. de S. (2007), “Animação Sociocultural em Portugal”, in Animador Sociocultural: Revista Iberoamericana, vol. 1, n.ำ 1, outubro de 2006 a fevereiro de 2007 (www.lazer.eefd.ufrj.Br/ animadorsociocultural/pdf/ac105.pdf).

LOPES, M. de S. (2008a), "Os Perfis Profissionais da Animação Sociocultural em Portugal”, in V. Ventosa (2008), Los Agentes de la Animación Sociocultural: el Papel de las Instituciones, de la Comunidad $y$ de los Profissionales, Madrid, Editorial CCS, pp. 457-485.

LOPES, M. de S. (2008b), “A Animação Sociocultural: os velhos e os novos desafios”, in J. D. L. Pereira et al. (coords.), A Animação Sociocultural e os Desafios do Século XXI, Chaves, Intervenção Associação para a Promoção e Divulgação Cultural, pp. 147-158.

MARTINHO, T. D. (2010), “Trabalho no Setor Cultural - Dois Tópicos em Foco: Flexibilidade e Regulação”, in M. ㄹ de L. L. Santos e J. M. Pais (orgs.), Novos Trilhos Culturais: Práticas e Políticas, Lisboa, ICS - Imprensa de Ciências Sociais, pp. 243-247.

MELO, D. (2001), Salazarismo e Cultura Popular (1933 - 1958), Lisboa, ICS - Instituto de Ciências Sociais da Universidade de Lisboa. 
Ó, J. M. N. Ramos do (1993), o Dispositivo Cultural nos Anos da "Política do Espírito" (1933-1949), Mestrado de História dos Séculos XIX e XX (secção do século XX), Lisboa, Faculdade de Ciências Sociais e Humanas da Universidade Nova de Lisboa.

Ó, J. M. N. Ramos do (1999), Os Anos de Ferro: O Dispositivo Cultural Durante a "Política do Espírito" (1933-1949), Lisboa, Editorial Estampa.

PAIS, J. M. (2005), Ganchos, Tachos e Biscates - Jovens, Trabalho e Futuro, Porto, Ambar.

PEREIRA, J. C. S. (1988), O Trabalho Temporário - Excepção ou Regra na Prática Contratual, Coleção Estudos, Instituto do Emprego e Formação Profissional.

QUINTAS, S. e M. Castaño (1998), Animación Sociocultural. Nuevos enfoques, Salamanca, Amaru Ediciones.

ROSAS, F. (1994), O Estado Novo (1926-1974), 7.ํvolume da História de Portugal (Direção de José Mattoso), Lisboa, Círculo de Leitores.

SANTOS, M. a de L. L. dos (coord.) (1998), As Políticas Culturais em Portugal, OAC - Observatório das Actividades Culturais.

STRAUSS. A. (1992), La Trame de la Négociation - Sociologie Qualitative et Interactionnisme, Paris, Éditions L’Harmattan.

THÉRY, H. (1970), “L'animation dans la societé d'aujourd'hui”, in Recherche Sociale n.ํ32, 1970.

THÉVENOT, L. (2006), L'Action au Pluriel - Sociologie des Régimes d'Engagement, Paris, La Découverte.

TRACANA, M. ․ E. (2006), “A importância do Animador na Sociedade Atual”, in Anim'arte: Revista de Animação Sociocultural, XIV, 61, 2006, pp. 12-13.

TRILLA, J. (coord.) (2004), Animação Sociocultural - Teorias, Programas e Âmbitos, Lisboa, Instituto Piaget.

VALENTE, J. C. (1999), Estado Novo e Alegria no Trabalho: Uma História Política da FNAT (1935-1958), Lisboa, Edições Colibri - INATEL.

VENTOSA, V. J. (2007), “Animação Sociocultural na Europa”, in A. N. Peres e M. de S. Lopes, Animação Sociocultural - Novos Desafios, Associação Portuguesa de Animação e Pedagogia (APAP), pp. 201-220.

VENTOSA, V. J. (coord.) (2006), Perspetivas Actuales de la Animación Sociocultural: cultura, tiempo libre y participación social, Madrid, Editorial CCS.

ŽIŽEK, S. (2007), Le Sujet qui Fâche - Le Centre Absent de l'Ontologie Politique, Paris, Flammarion.

\section{NOTAS}

3. Dicionário da Língua Portuguesa Contemporânea da Academia de Ciências de Lisboa.

4. Decreto-Lei n.o 25495, de 13 de junho de 1935 - diploma de criação da FNAT.

5. António Barreto, Expresso de 11 de julho de 1998, cit. in Lopes, 2006: 239.

6. A FNAT passou a denominar-se INATEL em 3 de abril de 1975.

7. António Barreto, Expresso de 11 de julho de 1998, cit. in Lopes, 2006: 276.

8. Jornais, revistas, atas de congressos e encontros, fóruns de discussão e blogs. 
9. Foram efetuadas oito entrevistas ao longo do mês de julho de 2010: quatro a Animadores Socioculturais com formação superior, duas a professores do curso de licenciatura em Animação Sociocultural, uma a um dirigente associativo e uma a um estudante finalista do curso de licenciatura em Animação Sociocultural.

1. Ele surge no âmbito do projeto de doutoramento Animação Sociocultural, Atores e Controvérsias Públicas, a decorrer na Faculdade de Ciências Sociais e Humanas da Universidade Nova de Lisboa e cujo objetivo é perceber a maneira como os Animadores Socioculturais orientam e ajustam a sua ação em face do caráter justo ou injusto das situações concretas de trabalho com que se vão deparando.

2. Animadores Socioculturais com formação superior, alunos finalistas de cursos de licenciatura em Animação Sociocultural, professores desses mesmos cursos e dirigentes das associações que representam os Animadores Socioculturais.

\section{RESUMOS}

O presente artigo $^{1}$ tem como propósito dar conta das problemáticas suscitadas no seio da Animação Sociocultural e, ao mesmo tempo, das posições que assumem os seus atores ${ }^{2}$ nas controvérsias públicas em que se envolvem em torno dessas mesmas problemáticas. Aborda-se, em primeiro lugar, a Animação Sociocultural enquanto atividade de intervenção social, educativa e cultural: a sua imprecisão, a sua ambiguidade e a incerteza que esta atividade comporta. Em seguida, relaciona-se a Animação Sociocultural com as transformações ocorridas na sociedade. Por último, evidenciam-se as problemáticas existentes, a diversidade de posições que os atores da Animação Sociocultural assumem perante essas mesmas problemáticas e, ainda, a diversidade de meios utilizados para a sua expressão pública.

This article aims to give an account of the issues raised within the Sociocultural Animation and, at the same time, the positions their players take in public controversies in which they engage around these same issues. Covers up, first, the Sociocultural Animation intervention activity while social, educational and cultural: its vagueness, it's ambiguity and the uncertainty this activity entails. Then it relates Sociocultural Animation to the changes occurring in society. Finally, the existing problems are shown and also the diversity of positions that actors of Sociocultural Animation take before such problems, as well as the variety of means used for its public expression.

\section{ÍNDICE}

Keywords: sociocultural animation, pragmatic sociology, public controversy, rules of engagement in public

Palavras-chave: animação sociocultural, sociologia pragmática, controvérsias públicas, regime de envolvimento em público 


\section{AUTOR}

\section{ANTÓNIO MANUEL RODRIGUES RICARDO BATISTA}

Doutorando em Sociologia, área de especialização em Cultura, Conhecimento e Educação (FCSH,UNL), Mestrado em Sociologia, área de especialização em Conhecimento, Educação e Sociedade (FCSH,UNL), Licenciatura em Sociologia (ISCTE-IUL). Experiência profissional: áreas do emprego, da educação e da formação profissional. Atividade profissional atual: Sociólogo no Gabinete Técnico da Fundação Monsenhor Alves Brás; investigador/colaborador do CesNova Centro de Estudos de Sociologia da Universidade Nova de Lisboa (grupo de trabalho: Mundos Sociais, Trajetórias e Mobilidades); professor do ensino secundário profissional na Escola Profissional de Agentes de Serviço e Apoio Social (aricardo1959@gmail.com) 